\title{
Wittgenstein and the Memory Debate ${ }^{1}$
}

\section{Danièle Moyal-Sharrock}

\begin{abstract}
In this paper, I survey the impact on neuropsychology of Wittgenstein's elucidations of memory. Wittgenstein discredited the storage and imprint models of memory, dissolved the conceptual link between memory and mental images or representations and, upholding the context-sensitivity of memory, made room for a family resemblance concept of memory, where remembering can also amount to doing or saying something. While neuropsychology is still generally under the spell of archival and physiological notions of memory, Wittgenstein's reconceptions can be seen at work in its leading-edge practitioners. However, neuroscientists, generally, are finding memory difficult to demarcate from other cognitive and noncognitive processes, and I suggest this is largely due to their considering automatic responses as part of memory, termed nondeclarative or implicit memory. Taking my lead from Wittgenstein's On Certainty, I argue that there is only remembering where there is also some kind of mnemonic effort or attention, and therefore that so-called implicit memory is not memory at all, but a basic, noncognitive certainty.
\end{abstract}

\section{Introduction}

There is the idea that for memory the thing must be written in the brain. But need memory be like reading old writings? (LPP 90)

Explicit reference to Wittgenstein is made in the psychological literature on memory, but perhaps not enough to warrant the claim which I want to make here, that his thought has infiltrated and decisively impacted the subject. And yet, to speak of Wittgenstein's contribution to the memory debate is to speak of a philosopher's elucidation, which is to say that even where the elucidation is not always or fully acknowledged, it can have unsettled the fundaments and reset the direction of research. It would take a separate study to fathom how philosophy does make such a mark on the (human) sciences, but in Wittgenstein's case, the mystery dissipates when we realize that his contribution is better measured in terms of a paradigm shift than by

\footnotetext{
${ }^{1}$ I am greatly indebted to Jason Leboe, Steve Lindsay, Ulrich Miller and Tim Racine for their invaluable comments on an earlier draft of this paper. I am also grateful to audiences at the universities of Barcelona and Hertfordshire.
} 
way of explicit recognition ${ }^{2}$. So that psychology can have changed course whilst not necessarily aware of the source of change.

Wittgenstein has produced this paradigm shift by shedding suspicion on, and hence destabilizing, Cartesian premises of thought and Platonic methods of thinking. He has achieved this through a demystification of 'the inner' and a correlated emphasis on action; a resistance to explanatory ghostly mental processes that themselves remain unexplained; and an unprecedentedly broad appeal to context or use in the determination of meaning, understanding, and memory. Because of Wittgenstein, physicalists and functionalists throughout the humanities and the sciences have had to abandon the quest for neat, unitary, and closed concepts and accommodate the ineluctable input of broad context into their models - indeed, going as far as seeking to physiologically incorporate it in their models; as, for instance, Alan Parkin who claims that the diencephalic region may be 'crucial for enabling context to be incorporated into memory' (1999, 12). Neuroscientists have also started trading ontologically full-blown entities (e.g. the will, intention, expectation) for ways of acting; and biologically full-blown entities (e.g. memory) for capacities.

The immediate concern of this paper is to show how Wittgenstein's rejection of the old models and his conceptual elucidation of memory have impacted on neuroscientific research, and should continue to do so. As we shall see, leading-edge neuroscientists are coming to the same conclusions about memory that Wittgenstein came to more than half a century ago. In that light, whether we choose to see Wittgenstein as having merely anticipated or actually impacted that research, his as yet unechoed thoughts on memory will seem all the more worthy of attention.

I begin, in the first two sections, by highlighting Wittgenstein's insights, which take the form both of questionings and of outright claims on memory. The third section comprises a brief account of current neuroscientific conceptions of memory. In the fourth section, I underline the problem perceived by some neuropsychologists in calling implicit memory systems, memory systems at all. I then show how the noncognitive certainty depicted by Wittgenstein in On Certainty provides a revolutionary and viable alternative to so-called 'implicit memory'. In section 5, I

\footnotetext{
2 Though there has been that too: e.g. Chapman, M. \& Dixon, R. (eds) Meaning and the Growth of Understanding:Wittgenstein's Significance for Developmental Psychology (Berlin: Springer-Verlag, 1985).
} 
conclude with a proposal that we not attribute to memory, or call mnemonic, any activity that requires no effort or attention.

\section{Clearing the Way: Memory Traces \& Memory Storage}

Whatever the event does leave behind in the organism, it isn't the memory. (RPP I, 220)

In 1946-47, Wittgenstein wrote the following passage:

I saw this man years ago: now I have seen him again, I recognize him, I remember his name. And why does there have to be a cause of this remembering in my nervous system? Why must something or other, whatever it may be, be stored-up there in any form? Why must a trace have been left behind? Why should there not be a psychological regularity to which no physiological regularity corresponds? If this upsets our concepts of causality then it is high time they were upset. (RPP I, 905)

It is passages like this that have earned Wittgenstein the label: 'behaviourist' whilst also perpetuating the impression that he was on an exclusively deconstructive mission, not concerned with offering constructive alternatives to the myths he was debunking. Certainly, Wittgenstein wants to alert us to the possibility that our conceptions of the mental are nothing but preconceptions: 'It is thus perfectly possible that certain psychological phenomena cannot be investigated physiologically, because physiologically nothing corresponds to them' (RPP I, 904; my emphasis); but his 'physiological agnosticism', as Michel ter Hark calls it $(1995,115)$, is not allencompassing:

No supposition seems to me more natural than that there is no process in the brain correlated with associating or with thinking; so that it would be impossible to read off thought-processes from brain-processes. I mean this: if I talk or write there is, I assume, a system of impulses going out from my brain and correlated with my spoken or written thoughts. But why should the system continue further in the direction of the centre? Why should this order not proceed, so to speak, out of chaos? (RPP I, 903)

Wittgenstein's intention here - or ever - is not to reject a psychophysical correlation between the brain and our mental activities; on the contrary, he assumes such a correlation. What he does reject is a 'psycho-physical parallelism' (RPP I, 906); that 
is, an isomorphic correlation (as Köhler would have it) between brain processes and thoughts or memories:

... nothing seems more possible to me than that people someday will come to the definite opinion that there is no copy in either the physiological or the nervous systems which corresponds to a particular thought, or a particular idea, or memory $^{3 \prime}$ (LW I 504; original emphasis).

Wittgenstein is not denying that we need brain activity for thought, and in that limited sense, remembering is causally dependent on the brain - on brain structures in different brain areas and on synaptic modifications in these areas - but it does not follow that these structures are representations of particular memories, stored and encoded in the brain. We must beware of confusing brain processes with thought processes:

Even if we knew that a particular area of the brain is changed by hearing God Save the King and that destroying this part of the brain prevents one's remembering the occasion, there is no reason to think that the structure produced in the brain represents God Save the King better than Rule Brittania. (LPP 90)

What Wittgenstein is, in fact, rejecting is the representational theory of mind, which stipulates that we need to have representations in the brain in order to remember, think etc. To think it can be possible 'to read off thought-processes from brain processes' (RPP I, 903) is to conflate brain reading with mind reading ${ }^{4}$, and retention with physical storage. But as Bennett and Hacker point out, although storage may sometimes imply retention, retention does not imply storage:

Memory, being the retention of knowledge acquired, is the retention of an ability to just the extent that knowledge itself is an ability - but it is not the storage of an ability. One may acquire and retain an ability, but that does not imply storage. For there is no such thing as storing an ability, even though there is such a thing as retaining the neural structures that are causal conditions for the possession of an ability. ... To remember that $p$ is to possess the information that $p$, but it is not to store or contain the information that $p$. One stores the

\footnotetext{
${ }^{3}$ In a paper of this length, I can only point to the ambiguity of the word 'memory' and not attempt to clarify it. In perusing the literature, it has seemed to me that this ambiguity and the frequent interchangeability of 'memory' with the equally ambiguous 'remembering', have obstructed research. A conceptual elucidation of these terms would hugely benefit the neuroscience of memory. The only elucidatory effort I have found is Endel Tulving's inelegant 'remembery' to denote the neural record of encoded information $(1993,294)$.
} 
information that $p$ if, for example, one writes it down, and stores the inscription in a filing cabinet or computer which then contains it. ((2003, 164-65)

(I shall later argue that remembering that $p$ is more than possessing the information that $p$.)

The brain, then, is a mechanical enabler, not the storehouse and codifier of our memories. Representationalism is the product of a misconstrued and mislocated causality. But as well as this misleading view of causality, which conflates causal conditions with causal representations, a narrow view of causality compounds our misconceptions of memory: we are loathe to envisage a causation that is not physiological. We therefore not only mistakenly take the brain to be recording what we see in an isomorphic trace or 'engram's, we also see this trace as having an activating function: it acts as mediator and activator between the original event and our ability to call it to mind. So that every time someone remembered an event, besides representing it, the trace would also select, decode and activate the memory. In this mediating capacity, the trace would play, for memory, a role analogous to that attributed to the pineal gland in our interactions between mind and matter/brain.

But, to localize (rightly or wrongly) a process, capacity or faculty is not yet to explain it ${ }^{6}$. The notion of memory traces seems to explain the source of memory, but all it does is offer the semblance of a physiological grip on a seemingly mystifying faculty; and so, we are left with what Norman Malcolm calls 'an illusion of explanation' (1977, 102). Wittgenstein's diagnosis of the need to postulate a physiological mediator between mind and brain is that our conception of causality is too narrow to admit a causality between psychological phenomena which is not mediated physiologically without this implying a belief in a gaseous mental entity (cf. RPP I, 906). A trace is required because, as Malcolm puts it, "'action at a distance" is a repugnant idea' $(1977,178)$. But, in fact, asks Wittgenstein: 'Why should not the initial and terminal states of a system be connected by a natural law, which does not cover the intermediary state?' (RPP I, 909). That is, in cases like someone's excessive ambition causing their loneliness; or greed causing someone to become corrupt, no

\footnotetext{
${ }^{4}$ And thereby to make a category mistake; for the brain is a material object, the mind a capacity.

${ }^{5}$ An engram is 'the transient or enduring change in our brain that results from encoding an experience' (Shacter 1996, 58).

${ }^{6}$ As David Stern puts it: '... postulating a place where mind meets matter is a deus ex machina which does not solve the problem, for it does nothing to explain how this interaction is possible' $(1991,205)$.
} 
physiological connection obtains, though many psychological connections do (and they are not gaseous: we know that greed can move people to criminal thoughts and criminal behaviour). Similarly, no physiological connections link my last year's trip to Cambodia to the numerous recollections I have had of it since.

What, before Wittgenstein, is not envisaged, is that we make the connection. In fact, to suggest that the brain 'remembers' is to attribute to it an ability that only beings possess, and to commit what Bennett and Hacker call 'the mereological fallacy' - the fallacy of ascribing to a part of a creature (e.g. the brain) attributes that can logically only be ascribed to the creature as a whole (e.g. the human being) ${ }^{7}$. Memory is an ability, and it is an ability that beings have, not traces or brains. For, writes Wittgenstein, 'even if [remembering] showed us scenes with hallucinatory clarity, still it takes remembering to tell us that this is past' (RPP II, 592); it is not 'some feature of our memory image that tells us the time to which it belongs' (LWII, 5). And, he goes on: 'if memory shows us the past, how does it show us that it is the past? It does not show us the past. Any more than our senses show us the present' (RPP II, 593). It 'takes remembering to tell us that this is past' (RPP II, 592; my emphasis), and remembering is done by a person.

It is in this Wittgensteinian vein that Gianfranco Dalla Barba argues that there are no such things as mental representations or memory engrams because there is no homunculus there to interpret them and to provide memory traces with their relationship to a past event. Dalla Barba contends that current theories of memory are based on a paradox - what he calls the memory trace paradox; and that they trade on what he refers to as the fallacy of the homunculus (2000, 138-9). He argues that any theory which bases the possibility of recollection on the preservation of an event inside a trace is prey to the misleading assumption that time can exist in things. But of course, things are not in themselves temporal; 'they acquire a temporal dimension only in the presence of a person who goes to the trouble of making them temporal' (ibid., 139).

The paradox fleshed out by Dalla Barba is that the past is seen to derive from present elements (traces). But how is this done? This is where the homunculus comes

\footnotetext{
7 (2003, Part I, Chapter 3). A fallacy first noted by Aristotle: 'Yet to say that it is the soul which is angry is as inexact as it would be to say that it is the soul that weaves webs or builds houses. It is doubtless better to avoid saying that the soul pities or learns or thinks, and rather to say that it is the man who does this with his soul' (De An 408b12-15); and then Wittgenstein: 'Only of a human being
} 
in. Inasmuch as for something to be called memory it must be 'correct' memory and not confabulation or false memory, recollection must result from certain selection and verification mechanisms of the memory trace that are not subjective (i.e. voluntary and conscious). But to accept the hypothesis of unconscious monitoring mechanisms is precisely to fall into the homunculus fallacy: 'the contradiction of postulating the existence of a type of unconscious consciousness - unconscious monitoring mechanisms endowed with intentionality that select, evaluate, and reject false memories and provide conscious consciousness with only real memories' (ibid., 145). This is to attribute intentionality (i.e. conscious selection, decision, rejection) to an unconscious process. Nothing has been gained, since we find ourselves with an unconscious made up of the same elements as a conscious subject; and what we had invoked to explain conscious memory now itself requires an explanation (ibid., 1467). What Dalla Barba has done here is flesh out the Wittgensteinian insight that remembering can only be done by a person.

The most pervasive conception of memory is that of a storage space in which representations of past events are stored. Here, writes Wittgenstein in the Brown Book, remembering is thought of as 'a peculiar state of the person's brain' (BrB 118) paradigmatically resulting from a process of comparison of reality with a stored picture or representation ( $\mathrm{BrB}$ 85-6). Of course, we do sometimes have mental pictures that help us remember, and we do compare these with reality, but because such mental images sometimes exist, we think that remembering necessarily involves them (RPP I, 1050) and essentially consists in comparison and identification. But as early as 1933-34, Wittgenstein rejects this unitary model of memory. In the Ambrose Lectures, he writes:

Different sorts of memories are to be distinguished. One kind passes in time, cinematographically. Another is like an image given all at once, but afar off. And we must not fail to take account of the kind of memory which consists in remembering a poem or tune rather than some event of the past. In these cases "to remember it" means "to be able to reproduce it". (AWL 56)

There is no one conception, picture or metaphor that will render the multifarious ways in which we remember something and, more importantly, Wittgenstein unprecedently affirms that, in remembering, our behaviour - what we 
say and do - is just as important as what we 'see'; as, that is, any introspection or retrospection that might occur: "The memory image and the memory words are on the same level' (RPP I, 1131).

\section{Wittgenstein's lead: memory as a way of acting}

Difficulties in philosophy constantly occur in cases where there is claimed to be a special state of mind for which a word stands. The further one goes from states of mind to activities, say, the simpler the physical difficulties become. (AWL 56)

Whereas we feel that saying or doing something cannot be all there is to memory; that it leaves out the essential feature of the mental process of memory and gives us only an accessory feature (cf. BrB 86), Wittgenstein stresses that 'memories ... in language are not mere threadbare representations of the real experiences's (PG 131), but that words, as well as gestures, can constitute remembering. Remembering can amount to 'doing something' such as reciting a poem by heart or fetching someone's key for them; just as recognizing someone can consist in saying "Hello!" to them in words, gestures, facial expressions, etc. (BrB 165-6):

Remembering, then, isn't at all the mental process that one imagines at first sight. If I say, rightly, "I remember it," the most varied things may happen; perhaps even just that I say it. (PG § 42)

Wittgenstein is not suggesting that there can be no mental process of remembering. He is rejecting only that 'peculiar' mental state which is thought to necessarily occur along with or in advance of the expressions (utterances, gestures etc.) of memory. For, there is in fact nothing that necessarily prefaces, accompanies or causes any remembering behaviour, such as saying a poem by heart:

Note also how sure people are that to the ability to add or to multiply or to say a poem by heart, etc., there must correspond a peculiar state of the person's brain, although on the other hand they know next to nothing about such psychophysiological correspondences. (BrB 118)

hears, is deaf; is conscious or unconscious' (PI 281).

8 Indeed, Wittgenstein even suggests that the capacity for memory necessitates the capacity for linguistic expression: 'Anyone with a soul must be capable of pain, joy, grief, etc. etc. And if he is also to be capable of memory, of making decisions, of making a plan for something, with this he needs linguistic expression' (LW II, 67). 
On Wittgenstein's view, we are warranted in speaking of a memory act if by it we do not mean a ghostly, amorphous mental event that necessarily accompanies or causes an expression or act of recall:

In remembering a poem we do not first visualize the printed poem and then say it. We simply start off by saying it, and the puzzling thing is the lack of any transition. (AWL 56)

If someone remembers his hope, on the whole he is not therefore remembering his behaviour, nor even necessarily his thoughts. He says - he knows - that at that time he hoped. (RPP I, 468; my emphasis)

These hardly resemble mental consultations of mental archives.

Wittgenstein's major contribution to the elucidation of the concept of memory is his discrediting the picture of memory as information storage and boldly replacing it with the idea that memory is nothing but an ability and that, in some contexts, remembering amounts to a way of acting; that is, to an act or expression which does not result from introspection or retrospection (e.g. BrB 85). The input of context is essential here. What gives a gesture or an utterance their mnemonic status is not any property they may have, or any mental representations they are based on, but their context: it is context that makes an act (say, a smile or a nod) a memory act, rather than, say, an act of politeness. As Malcolm suggests: 'A smile and a greeting would reveal recognition in one context, but just friendliness in another' $(1977,53)$.

Since Wittgenstein, neuroscientific theory on memory has evolved, though not in choral unison. If 'scientists agree that the brain does not operate like a camera or a copying machine' (Schacter 1996, 40), most of them still speak of memory as stored and encoded ${ }^{9}$ even as they also speak of it as an ability. Although, as we have seen, the science on memory is catching up with Wittgenstein's insights, Dalla Barba's revolutionary stride is not the norm. This is not to say that he is a maverick, but let's have a look at the mainstream, before going on to more Wittgenstein-inspired conceptions of memory.

\section{Current Neuroscientific conceptions of memory}

\subsection{The Multiple Systems approach: classifications of memory}

\footnotetext{
9 E.g. Tulving, who speaks of 'stored information' in some memory systems as 'representational isomorphic with what is, or could be, in the world' $(2005,11)$.
} 
In neuropsychology, the notion of memory as a single faculty of the mind has mostly given way to a multiple systems or structuralist approach, where memory is no longer seen as stored in one memory system, but in different 'storage sites', corresponding to various memory systems.

A major distinction was drawn in 1972 by Endel Tulving between what he called episodic (or autobiographical memory) ${ }^{10}$ and semantic memory. Episodic / autobiographical memory is memory for personally-experienced events. It enables us to answer questions such as 'What did you have for breakfast?' or 'Where did you park your car?' and is associated with a qualitatively distinct consciousness or experiential awareness. Semantic memory comprises the general, basic, stable knowledge about the world and language that we share with our community, such as knowing the meaning of the word 'bottle', what a stop sign means, or what we do in a restaurant. Semantic memory is of things we recall without any sense of when we learned or experienced them.

Yet, classification between episodic / autobiographical and semantic memory has proved problematic. For one thing, 'semantic memory also forms the basis for a good deal of personal autobiographical knowledge' (Schacter 1996, 151); and for another, some items of allegedly autobiographical memory, such as telling someone your name, do not require experiential awareness at recall. In 1992, Alan Baddeley asked:

If you tell me your name, is that a piece of autobiographical memory? If you remember a list of words I have just presented, is that autobiographical memory? (Baddeley 1992, 13)

Finding it difficult to neatly distinguish between episodic and semantic memory, and finding also that these did not cover all types of memory, neuropsychologists effected a more comprehensive and viable division between declarative (or cognitive memory) - which subsumes both the episodic I autobiographical and semantic memory just mentioned - and nondeclarative (or procedural memory $\left.{ }^{11}\right)$. Declarative memory, also defined as a 'knowing that', is a memory for facts and events that can be consciously accessed (inspected) and verbalised (declared) irrespective - now - of whether they are autobiographical

\footnotetext{
10 Though this interchangeability is now being questioned; cf. Tulving (2002), 271.
} 
recollections or pieces of general knowledge (Parkin 1997, 20). It is sometimes also called 'explicit memory' (Squire 1999, 521). Nondeclarative / procedural memory is viewed as an action system or a know-how: its operations are expressed in performance and can occur independently of cognition; they do not require the kind of conscious awareness that characterizes other forms of memory (Tulving 1993, 286). Not consciously accessible or verbalized, nondeclarative memory is used in acquiring, retaining and performing cognitive, motor and perceptual skills (e.g. speaking your native language, riding a bicycle, recognizing faces); it is involved in training and the development of habits and is sometimes also called 'implicit memory' (Squire 1999, $521,390)$.

Besides persistent problems of overlapping classifications, a more fundamental perplexity is plaguing neuroscientists. They are not always clear, consistent or sure about whether these classifications are meant to refer to biological parts of the brain, or are simply theoretical machinery: 'No one has much doubted the usefulness of the concept of episodic memory for classificatory ("bookkeeping") purposes, but there has been considerable resistance to the idea that it represents anything special in biological reality', writes Tulving $(2005,8)$. The considerable resistance he is referring to comes from (Neo-)functionalists, the new contenders in the memory arena. Countering the general assumption that memory systems refer to biologically real entities or structures, they claim that distinctions between memory systems are not based on a direct morphological analysis of the structure of memory, but are in fact derived from a functional or task-based analysis; and that this leads to a fundamental circularity in the explanation of memory. As this suggests, the new debate on memory is between multiple systems analysts (structuralists) and functionalists; unitarians are fading out of the picture.

\subsection{Functionalism: memory as an ability and an activity}

[...] remembering is something a person does. Ian Hunter (1957), 18

In spite of their name, (neo-)functionalists, are not to be associated with Functionalism à la Fodor. For them, the major problem with system-based approaches is that these take memories to be concrete entities instantiated in a mental or neural

\footnotetext{
11 In fact, 'nondeclarative memory' is a larger category, which subsumes procedural memory, but these terms are often used interchangeably, and I will use them thus here.
} 
representation. In this, multiple analysts miss the very nature of memory, because to see memory in a representation is to freeze in time and space what is in essence a fluid activity that is spread across both (Toth \& Hunt 1999, 256, 264):

Like walking, memory is a dynamic event that exists only in its operation. [...] one could say that when we are not experiencing (or recollecting) a prior event, or otherwise being ('implicitly') influenced by that event, memory is, 'strictly speaking, non existent'12. (Ibid., 257)

Functionalists hold that memory is an ability that manifests itself in action: 'memory is not an abstracted copy or representation of some previous content but is simply the set of operations used in dealing with [an] event. There is nothing else' (ibid., 263; my emphasis). As Ian Hunter, functionalist before his time, remarks: in testing someone's claim that they have an excellent memory, we do not observe anything which could be called a memory, but watch the person as he does something, namely repeat or try to repeat the page he has read: 'In short, we have concerned ourselves not with an object but with activity; not with his memory but with his activities of learning and remembering' (1957, 13). This smacks of Wittgenstein's and Ryle's de-reification of intentional concepts, and of Wittgenstein's explicit rapprochement between memory and acting. Indeed, Norman Malcolm's book on memory - itself heavily indebted to Wittgenstein - is referenced in Toth and Hunt's paper.

Most neuroscientists, now speak of memory as an ability. This should preclude - but unfortunately does not - their also regarding memory as stored; only functionalists seem to have rejected the notion and image of memory storage, and speak exclusively of memory as an ability or function, and its occurrences as activities or (trans)actions. On the functionalist view, then, memory is an ability which manifests itself as a transaction between a person and a context of recall, or 'retrieval environment' (Toth \& Hunt, 263). Indeed, memory is seen as no longer definable outside a 'retrieval' environment:

When we say that memory reflects an interaction between a person and a retrieval environment, we mean quite literally that memory cannot be discussed

\footnotetext{
${ }^{12} \mathrm{Cf}$. also Hunter: although everyday speech suggests that memory is an object we possess in the same way as we possess a head or a big toe, 'it is true, although alarming, to say that there is no such thing as memory' $(1957,13)$.
} 
in the abstract, outside of the context of retrieval cues and [...] the goals of the remember. (ibid., 258)

There is no question, then, that Wittgenstein's deflation of representationalist accounts of memory and its correlated emphasis on the context-sensitivity, or indeed the contextuality or situatedness, of memory have informed theorists and prompted, in Toth and Hunt's words, 'the relocation of memory from something that exists "in" the person or brain to something that obtains in the interaction between the person (and their brain) and the environment in which acts of memory occur' (ibid., 257).

Far from the 'snapshot' account of memory, the functionalist approach defines memory as 'a doing' (ibid., 255). By this, it is often meant that memory is situated or external. I shall not here enter the buoyant and variegated field of embodied or embedded or extended mind, but one direction of research might be worth noting, in which memorization is viewed as imprinting-like learning behavior; and where emphasis is laid on the role that an agent's morphodynamics and situatedness play in the generation of such behavior (Izquierdo-Torres \& Harvey 2006). This is foreshadowed by Wittgenstein's insight that remembering is often prompted by or embedded in certain acts, as expressed in this passage from the Lectures on Philosophical Psychology:

I draw a curve on paper when the man speaks; when I trace the curve again I can repeat the sentence; but the curve can't be read as a code. (LPP 90)

Retracing the curve is here a necessary condition for recall, but Wittgenstein insists that it is not any representative nature the curve would have acquired that makes it thus necessary - 'the curve can't be read as a code'. Nor would Wittgenstein have agreed with extended mind theorists that such examples of situated and embodied memory are mere cognitive scaffolding, or that they are, as writes Andy Clark, 'best seen as alien but complementary to the brain's style of storage and computation' (1997, 220; original emphasis). For Wittgenstein, retracing the curve can be a sufficient condition for recall.

In a passage of the Remarks on Philosophical Psychology, Wittgenstein imagines someone making marks and lines on paper that will help him remember a text that is being recited to him; these jottings are not writing, not connected by rules with the words in the text and yet 'without these jottings he is unable to reproduce the text'; these jottings would 'not be a rendering of the text, not a translation, so to speak, 
in another symbolism. The text would not be stored up in the jottings. And why should it be stored up in our nervous system?' (RPP I, 908).

\title{
4. Implicit vs. Explicit Memory
}

\begin{abstract}
Do babies "remember" their past encounters with a mobile when they kick spontaneously, or are they showing some form of implicit memory, perhaps a procedural or motor response? (Schacter 1996, 174).
\end{abstract}

Although there is still today in the science of memory a great deal of interest in encoding and storage, the focus is now on retrieval (Tulving 2002, 271), and therefore on use. Memory is now often defined as 'the faculty to use any type of acquired information' (Dalla Barba, 2000, 138). Explicit memory is said to be at work when a person intentionally or consciously recollects something, whereas implicit memory refers to the unintentional, nonconscious use of previously acquired information (Schacter \& Tulving 1994, 11-12). As noted earlier, implicit memory is sometimes used synonymously with procedural memory or know-how. It is claimed to be evolutionarily more primitive than explicit memory, and is attributed to animals and infants. It is thought to be at work in conceptual domains (e.g. accessing words) as well as perceptual ones (e.g. recognising faces) (Schacter 1996, 189). And when past experiences unconsciously influence our perceptions, thoughts, and actions, such as riding a bicycle or playing the piano effortlessly, this is also said to be due to implicit memory (Schacter 1996, 5) - though we are warned not to confuse implicit memory with the Freudian unconscious (ibid. 190-1).

It is clear, then, that implicitness and absence of awareness do not prevent theorists from thinking it is a kind of memory that is here in question:

[...] As we have come to learn that memory is not one single thing, we've opened up a whole new world of implicit, nonconscious memory that underlies our abilities to carry out effortlessly such tasks as riding a bicycle or playing a piano, without having to direct each movement consciously every time we attempt the task. (Schacter 1996, 5; my emphasis)

But there are signs of worry. According to Roediger et al:

... the non-declarative memory systems begin stretching our usual notion of memory. If you get up from your chair to leave the room, do you 'remember' how to walk? When you reach down to tie your shoelaces, do you have to remember how? When you streak across the court to execute a forehand volley, do you have 
to remember how to do so? Using the word 'remember' seems strange in these contexts? $(1999,39)$.

And Alan Baddeley wonders whether the whole range of implicit learning systems that have been contrasted to the episodic system 'should be referred to as memory systems at all, as they typically involve relatively automatic retrieval processes that are often not under the direct control of the subject' (1999, 516; original emphasis).

\subsection{Reconceptualizing, from Wittgenstein}

Baddeley's and Roediger's worry has not made waves. Neurologists still generally believe that 'we often remember information without being aware of it' $(1999,17)$. Even Toth notes that 'any serious account of memory must acknowledge the dramatic difference that obtains between "memory with awareness" and "memory without awareness"' (2000, 245; my emphasis). In opposition to what is the default assumption in neuropsychology ${ }^{13}$, I want to suggest that without some kind of awareness, it isn't memory that we are talking about. This is not to say that memory necessitates awareness of the recollective experience (what Tulving calls autonoetic remembering). It $i s$ to say that to put under the banner of memory the mere use of knowledge acquired in the past is to, as it were, under-employ the concept of memory; to employ it merely because the knowledge in question was acquired in the past. With Wittgenstein's help, I now want to argue that being unconsciously or implicitly influenced by our experience of a prior event does not warrant speaking of memory ${ }^{14}$, and that memory should only be evoked in cases of attentive remembering, of effortful remembering, and of memorizing. So that what Ian Hunter refers to as 'that rapid, automatized and depersonalized recalling which is typical for material that, as we say, we know well' $(1957,31)$ is, on my view, not a recalling at all.

Baddeley's and Roediger's worry is that, at the procedural level, our usual notion of memory is being stretched. Wittgenstein would certainly share that worry. He would agree that we should, in nonpathological cases, no more call riding a bike a case of 'remembering' than we should call walking a case of 'remembering'. So that

\footnotetext{
${ }^{13}$ Cf. e.g. Tulving (1993); Schacter (1996, p no); but also Toth \& Hunt $(1999,257)$.

14 What about the Freudian unconscious? However much our present behaviour and personality are (adversely) affected by our past experiences, those experiences cannot be said to be stored in memory (memory is not a storage space, and experiences cannot be stored). When impressions or pictures from the past present themselves to us (prodded or unprodded), we rightly speak of remembering or of memory, but it does not follow that these memories had been previously stored as unconscious memories.
} 
unless we are children learning, or adults relearning (after, say, a stroke), to walk or tie our shoelaces or ride a bike, these are all skills that we've acquired and perform without the use of memory. We do not, as normal adults, remember how to walk, tie our shoelaces, or ride a bike before or during our performance of these things. In such cases, we would not speak of memory, but of know-how, skill, or capacity.

Wittgenstein's worry, however, would not be limited to the procedural level; he would protest that our usual notion of memory is being stretched across all the socalled memory systems, and that many manifestations of so-called declarative memory - semantic and autobiographical (or episodic) - should not be regarded as manifestations of memory at all. Throughout his work, Wittgenstein often excludes memory (or recognition) as necessarily prefacing our use of words and skills, and he generally regards memory as superfluous in most explanations. But more specifically in his last work, On Certainty, he logically excludes it - and in fact, any other epistemic process - from prefacing our assurance about any of our basic beliefs - such beliefs as are included by neuroscientists in semantic and autobiographical memory.

Very briefly: in On Certainty, Wittgenstein takes our basic beliefs or certainties to be ungrounded, unjustified certainties: 'At the foundation of wellfounded belief lies belief that is not founded' (OC 253). He compares these basic beliefs to 'hinges' on which the door of inquiry turns ${ }^{15}$, making them noncognitive certainties that logically underpin our cognitive inquiries. Some of these certainties are natural, instinctual or animal-like certainties (OC 359) that are never taught, or even articulated as such - that is, not articulated qua certainties; e.g. 'I have a body', 'I can move', 'I cannot walk through other people'. Such sentences are only artificial verbal renderings of what are in fact nonpropositional certainties: here, to be certain does not imply that one can formulate the sentences or even understand the words that compose them. A one-year old child not yet in possession of language shows that she is endowed with such certainties by using her body, reacting to other people, avoiding people rather than attempting to walk through them etc. ${ }^{16}$ Other hinges are acquired,

\footnotetext{
15 I have elsewhere (cf. Moyal-Sharrock 2004/2007, Chapter 5) classified these into linguistic, local, universal and personal hinges. It turns out that these classifications roughly correspond to what is deemed to be the content of semantic memory (linguistic, local, universal hinges), and episodic (or autobiographical) memory (personal hinges).

16 Later, when she comes to use language, hinges will regulate the child's speaking within the bounds of sense in the same way they now regulate her acting within the bounds of sense. It must be stressed that Wittgenstein sees logic or grammar as rooted in instinct and action: "I want to regard man here as an animal; as a primitive being to which one grants instinct and ratiocination. As a creature in a primitive state. Any logic good enough for a primitive means of communication needs no apology from
} 
but where hinges are acquired, assimilation is effected through some form of conditioning, not propositional learning. They are either explicitly acquired - e.g. through cultural training or educational drill (e.g. 'This is (what we call) the sky'), or they are implicitly assimilated - without any training or often no formulation at all through something like repeated exposure (e.g. 'People sometimes lie'). So that, although we can put them into words for heuristic purposes, such as pedagogical training or philosophical discussion, these basic certainties are nonpropositional and ineffable qua certainties. They only show themselves in what we say and do.

The next two sections aim to show that some of what neuropsychologists call semantic and autobiographical memories are in fact basic certainties that are not susceptible of recall in ordinary (e.g. nonpathological) circumstances. This is not to say that these certainties cannot be modified or rendered obsolete (and would then be susceptible of recall). If, say, it were decreed that the word 'table' would be replaced in English usage by another word, we would unlearn the word 'table', such that in twenty years it may well require some effort to recall it. Hinges can be unhinged, but as long as they are hinges, they are not susceptible of recall - or forgetfulness: 'Suppose a man could not remember whether he had always had five fingers or two hands? Should we understand him? Could we be sure of understanding him?' (OC 157). Any 'forgetfulness' here, or even (genuine) hesitation, would be the sign of 'a mental disturbance, perhaps a transient one' (OC 71) ${ }^{17}$.

\section{2 'Semantic' Hinges}

... neither do the spoken words occur to me [when I'm reading] as if, say, something reminded me of them. (PI 165)

What neuroscientists refer to as semantic memory comprises our general knowledge about the world, concepts, rules and language. This is covered first of all by

us. Language did not emerge from some kind of ratiocination" (OC 475). See also PG, pp. 62-3. This is the subject of my "Logic in Action: Wittgenstein's Logical Pragmatism and the Impotence of Scepticism", Philosophical Investigations 26:2 (April 2003), 125-148.

17 Similarly hinges are immune to mistake (but not to mechanical slips, such as slips of the tongue (OC 625 ) or to pathological confusion, both of which Wittgenstein prefers not to call 'mistakes'), 'In certain circumstances a man cannot make a mistake' (OC 155): 'How might I be mistaken in my assumption that I was never on the moon?' (OC 661); 'Can I be making a mistake, for example, in thinking that the words of which this sentence is composed are English words whose meaning I know?' (OC 158). By ruling out the possibility of mistake in such cases, Wittgenstein does not mean to rule out the possibility that someone might well believe that the words of which this sentence are composed are not English, or that they had been to the moon when they hadn't; only we 'should not call this a mistake, but rather a mental disturbance' (OC 71). 
Wittgenstein's linguistic certainties ${ }^{18}$. The trained assimilation of language produces an indubitable certainty about certain words:

We say: if a child has mastered language - and hence its application - it must (...) be able to attach the name of its colour to a white, black, red or blue object without the occurrence of any doubt. (OC 522)

And if there is no occurrence of doubt, this renders otiose the presence of remembering. Indeed, '[i]t is simply the normal case, to be incapable of mistake about the designation of certain things in one's mother tongue' (OC 630). Certain things, not all. What Wittgenstein is saying is that we cannot normally be mistaken or uncertain about the meaning of our most basic words. And here, the simplicity of Wittgenstein's examples is important; he uses words like 'table', 'chair', 'red', 'blue', not like 'funambulist' or 'perfunctory'. If I am a fluent speaker of English, I may hesitate, reflect, attempt recall before using words like 'funambulist' and 'perfunctory', but not before using words such as 'red' and 'table'. It is only at this basic level that Wittgenstein questions that our use of words involves memory:

When I talk about this table, - am I remembering that this object is called a "table"? (PI 601; original emphasis)

"Is it ever true that when I call a colour 'red' I serve myself of memory?? / make use of memory?/" (LPE 22)

Here, Wittgenstein outrightly questions the preconception that an act of memory always prefaces our use words (indeed, he wonders if it ever prefaces our use of some words). When as a child I first learned the use of the word 'table', I did make use of memory, but after years of repeated use and exposure, only a cognitive disorder could cause me to forget that this object is called a 'table'. Repetition has, as it were, drilled it into me: I no longer need, as I did when I first learned the word, to recall it each time; I utter it automatically, without a thought, the same way I get on a bicycle and start pedalling without having first to recall the technique I learned as a beginner. Once the technique is mastered - and this is not to say the mastery cannot break down or be deliberately modified - there is no question of appeal to memory. Our certainty

18 Or so I have called them. Examples from On Certainty are: ' $2 \times 2=4$ ', 'What the colour of human blood is called', 'What is called "a slab" / "a pillar"', 'Which colour is meant by the word blue', 'The words composing this sentence are English' (OC 455, 340, 565, 545, 158) 
in using such words is not due to the implicit, instantaneous recall of rules prior to each use; it is a thoughtless know-how:

"Understanding a word" may mean: knowing how it is used; being able to apply it.” (PG p. 47)

"I can use the word 'yellow' is like 'I know how to move the king in chess'. (PG p. 49; my emphasis)

Wittgenstein's insight that the understanding of language, like that of a game is not a knowledge of rules, but more like the mastery of a calculus, an ability, came late to neuroscience on memory; only recently did performance on word identification come to be viewed as no longer reflecting semantic memory, but procedural memory (Toth \& Hunt 1999, 259). All that now needs to be done, I suggest, is to stop regarding this know-how as memory.

The same goes for our basic general knowledge ${ }^{19}$. Although we may have once learned that human beings die or that they have brains, once these facts have been assimilated they are no longer (in normal circumstances) objects of recall, or of any cognitive process. This is also true of perceptual hinges:

But when I say "It tastes exactly like sugar", in an important sense no remembering takes place. So I do not have grounds for my judgment or my exclamation. If someone asks me: "What do you mean by 'sugar'?" - I shall indeed try to show him a lump of sugar. And if someone asks "How do you know that sugar tastes like that?" I shall indeed answer him "I've eaten sugar thousands of times" - but that is not a justification that I give myself. (RPP II, 353)

For, this kind of certainty is basic (it has become basic through habituation) and therefore ungrounded - though others may demand grounds from us, we are not certain on the strength of any grounds (there is a first/third person asymmetry here). In unexceptional circumstances, we do not remember that this tastes like sugar or that this is a bottle or that what we do in restaurants is eat, drink etc. Our certainty about such things is as noncognitive and unjustified as a reflex action - which, again, is not

19 Covered in On Certainty by what I have classified as local hinges; e.g.: 'There is an island, Australia', 'The earth is round', 'Trains normally arrive in a railway station' (OC 159, 291, 339) - and universal hinges; e.g.: 'The earth exists', 'Things don't systematically disappear when we're not looking', 'If someone's head is cut off, the person will be dead and not live again', 'Trees do not gradually change into men and men into trees', 'I have a brain', 'I am a human being', 'I have forbears' (OC 209, 234, 274, 513,159, 4, 234). 
to say that our certainty cannot be unlearned or modified, the same way our reflexes can be retrained ${ }^{20}$.

\section{3 ‘Autobiographical (Episodic)’ Hinges}

$$
\begin{aligned}
& \text { If you tell me your name, is that a piece of } \\
& \text { autobiographical memory? (Baddeley 1992, 13) }
\end{aligned}
$$

Similarly, for Wittgenstein, basic autobiographical facts are not objects of memory, but noncognitive certainties that constitute the ungrounded starting points of what it makes sense for an individual to say of herself ${ }^{21}$. In On Certainty, he writes:

For months I have lived at address A, I have read the name of the street and the number of the house countless times, have received countless letters here and given countless people the address. If I am wrong about it, the mistake is hardly less than if I were (wrongly) to believe I was writing Chinese and not German. (OC 70)

Autobiographical certainties resemble truths which I know, but although, from a third-person perspective, these are truths which can be known, that is not how I relate to them. I do not have a cognitive rapport with my autobiographical certainties; they are not derived from reflection or memory.

If someone asks me what I have been doing in the last two hours, I answer him straight off and I don't read the answer off from an experience I am having. And yet one says that I remembered, and that this is a mental process. (RPP I, 105)

One might also marvel that one can answer the question "What did you do this morning?" - without looking up historical traces of activity or the like. Yes; I answer, and wouldn't even know that this was only possible through a special mental process, remembering, if I were not told so. (RPP I, 106)

For although one calls this 'remembering', it is no more remembering than the following is a case of recognizing: 'Asked "Did you recognize your desk when you entered your room this morning?" - I should no doubt say "Certainly!" And yet it would be misleading to say that an act of recognition had taken place' (PI 602).

\footnotetext{
20 Nor is the expression not susceptible of slips of the tongue, the way even the most expert typists mistype some words.

${ }^{21}$ E.g.: 'I come from such and such a city', 'For months I have lived at address A', 'I have never been on the moon', 'I have just had lunch', 'The person opposite me is my old friend so and so' (OC 67, 70, 419, 111, 659, 613) - these, I have called personal hinges.
} 
Some basic autobiographical facts - e.g. 'My name is Danièle', 'I live in London', 'I have no children', 'I speak French' - cannot, in normal circumstances, be the product of recall. That my automatic assurance of these facts is vulnerable to amnesia $^{22}$ does not make them, in non-pathological circumstances, a product of memory, or even disposed to be recalled ${ }^{23}$.

What is it then that makes some autobiographical facts hinge certainties, and others not? Why is my having been to Paris a hinge for me, not susceptible of error or hesitation or recall (though, of course, details of my individual stays in Paris are thus susceptible), but not my having been, say, to Montelimar? Absence of hesitation, automaticity may be achieved through repetition or drill, but they will be greatly assisted by a high degree of salience (proximity, familiarity, simplicity etc.). Paris has been salient in my life: I have lived, studied and lectured there; I regularly visit my Parisian friends and colleagues; have several times been to the Musée Guimet and the Louvre etc. But the fact that I can give a list of reasons for my certainty does not mean that I, myself, have come to this certainty from following a line of reasoning (again, first/third person asymmetry). As for Montelimar, I have often driven past it on my way to the south of France and remember the lure of its world-class nougat, but not whether it ever succeeded into making me swerve into the city.

Temporal and spatial proximity also contribute to hinge certainty: I may not be certain about which day last week I went to the theatre and may have to tax my memory to find out, but - all being otherwise well with me - I would have not a moment's hesitation about having been to the theatre an hour ago. I would no more

\footnotetext{
22 Amnesia affects some parts of the brain and those have been termed 'autobiographical memory', 'long-term storage', 'declarative memory' etc. This makes it sound as if amnesia is an erasing of the memory tape or an emptying of the memory box, whereas memory is an ability. It isn't that the film has gone blank or blurry, but that we are unable to recall. Again, as Bennett and Hacker explain, it isn't that declarative and non-declarative memories are stored in different brain areas, for there is no such thing as storing memories in the brain, but '[r]ather the capacity to remember various kinds of things is causally dependent on different brain areas and on synaptic modifications in these areas' $(2003,159)$. Here again, confusion results from the failure to distinguish the retention of an ability from the neural conditions for the possession of that ability, and from the storage of information in inscribed or otherwise recorded form $(2003,160)$ : ' $\ldots$ of course, it may well be the case that but for certain neural configurations or strengths of synaptic connections, one would not be able to remember the date of the Battle of Hastings and would not remember being told it. But it does not follow from that idea that what one remembers must be, as it were, written down in the brain, or that there must be some neural configuration in the brain from which one could in principle read off what is remembered. Nor can it be said that this neural configuration is a memory.' (ibid. 167).

${ }^{23}$ What is pathologically possible is not an indicator of norm. In normal circumstances, I am not cognitively certain of having a body, but noncognitively certain. Losing proprioception is a pathological condition that makes the only awareness I can have of my body a cognitive one, but this does not have any resonance on the normal case. For further discussion, see my (2004/2007, 127-29). For the same argument applied to autism and dyssemia, cf. Moyal-Sharrock (2007).
} 
hesitate or reflect here than I would to assert that I am not at the theatre right now or that I have often been to Paris. Any hesitation or forgetfulness here would translate not uncertainty, but some form of pathology.

\section{Mnemonic Effort and Attention}

I certainly agree with Jason Leboe (personal communication, 2007) that events in one's past determine our current success in engaging in virtually every thought and behaviour possible, but I do not find this reason enough to envisage every learned pattern of thought or behaviour as involving memory. The acquisition of these patterns may have involved memory at some point, and this may be ground enough to see them as continuing to be products of memory, but this is only trivial ground. To suggest that the degree of a current task's automaticity depends on how much experience has supported the performance of that task (and so the rapidity and efficiency of our current mental processes reflect the level of memory's contribution) is to say no more than that memory has played a role in the achievement of certainty, not that it continues to do so in the subsequent deployment of all our behaviour and thought.

Defining memory as 'the use of prior experience to guide current thought and behaviour' (Leboe 2007) or 'the faculty to use any type of acquired information' (Dalla Barba 2000, 138); and defining remembering as 'the use of knowledge retained' (Bennett \& Hacker 2003, 156) suggests that we use memory for just about everything we think and do, making memory so pervasive a concept as to be useless or meaningless. I suggest inserting the single word 'attentive' to these definitions, making memory 'the attentive use of prior experience to guide current thought and behaviour', thereby precluding speaking of remembering where there is only automaticity. To speak of memory, there must also occur what I would call mnemonic effort or, at least, mnemonic attention.

Examples of mnemonic efforts are concentration, focus or, more elaborately, the little tricks we use in trying to remember a name (e.g. I suspect it starts with the letter 'B', and run through the whole gamut: BA, BE, BO... until the word springs to mind: 'Borden!'); or in trying to recall what we set out to do (e.g. returning to the spot where we first thought of it). But what about unprompted memories - where one remembers a situation or occurrence 'at a moment' (RPP I, 837) - as when a mental picture of last night's family dinner, or a thought I had yesterday for this paper, 
spontaneously come to mind? Here, where no mnemonic effort is made, what we might call mnemonic attention is paid. That is, we attend to the mental picture of last night's dinner or yesterday's thought as something that is being, as it were, revisited as opposed, say, to an imagined picture, or to a thought never before envisaged. Indeed, the idea that a picture of last night's dinner must have been stored if it is to be able to spring to mind weakens its hold when we think that imagined pictures can, as it were, 'come from nowhere'. We think that a memory picture must have been stored because we think of it as a 'reproduction' or replica, which therefore must in some way contain the original. But not only do we usually remember the original scene or event with very little detail; and indeed, often misremember $i^{24}$, the idea that an imprint of the original must be stored in order for the original to be 'reproduced' is based on a mechanistic picture of human abilities, and on grammatical confusions often prompted by words like 'storage' and 'retrieval'.

What neuroscientists have called implicit memory seems to me very close to what Wittgenstein has described in On Certainty as an attitudinal assurance that is either instinctual or automatic, and that should therefore be envisaged not as a product of memory (in any nontrivial sense), but more in terms of reflex action. To the objection voiced to me that this attempt to oust automatic linguistic and nonlinguistic behaviour from the realm of memory seems alien to the Wittgensteinian spirit, which tends to expand rather than restrict concepts, I would reply that Wittgenstein has expanded where expansion was needed (cf. section 2), and that he never meant family resemblance concepts to be a carte blanche for groupings of heterogeneous concepts. Rather than contribute to the homogenisation of memory, I believe On Certainty shows differences to those who see memory everywhere.

\footnotetext{
${ }^{24}$ Exact reproduction and verbatim recall are rare instances of recall; they often demand by rote or focussed memorization, and are seldom conditions for successful remembering. As Tulving notes, memory can be absolutely veridical, as in memorized poems, speeches, dates, addresses, phone numbers and passwords that we can recall, but 'a good part of the activity of memory consists not in reproduction, or even in reconstruction, but in sheer reconstruction. And constructed memories do not always correspond to reality' $(2002,273)$.
} 


\section{References}

Baddeley, A.

(1999) 'Memory' MIT Encyclopedia of the Cognitive Sciences, 514-517.

(1999a) Essentials of Human Memory (Hove, UK: Psychology Press).

(2002) 'The Concept of Episodic Memory' in Baddeley et al (2002), 1-10.

Baddeley, A., Aggleton, J.P. \& Conway, M.A. (eds) (2002) Episodic Memory: New Directions in Research (Oxford: Oxford University Press).

Bennett, M.R. \& Hacker, P.M.S. (2003) Philosophical Foundations of Neuroscience (Oxford: Blackwell).

Clark, A. (1997) Being There: Putting Brain, Body, and World Together Again. (Cambridge, Ma: MIT Press).

Conway, M.A., Rubin, D.C., Spinnler, H., Wagenaar, W.A. (eds) (1992) Theoretical Perspectives on Autobiographical Memory (London: Kluwer Academic Publishers).

Dalla Barba, G. (2000) 'Memory, Consciousness, and Temporality: What Is Retrieved and Who Exactly Is Controlling the Retrieval?' in Tulving \& Craik (2000), 13855 .

Engel, S. (1999) Context is Everything \& the Nature of Memory (New York: W.H. Freeman).

Foster, J.K. \& Jelicic, M. (eds) (1999) Memory: Systems, Process, or Function? (Oxford: Oxford University Press).

Hacker, P.M.S. (1996/2000) Wittgenstein, Mind and Will, vol. 4 of an Analytical Commentary on the Philosophical Investigations. Part I: Essays (Oxford: Blackwell).

Hark, M. ter (1995) 'Electric Brain Fields and Memory Traces: Wittgenstein and Gestalt Psychology' Philosophical Investigations 18:1, 113-37.

Hunter, Ian M.L. (1957) Memory: Facts \& Fallacies (Baltimore: Penguin), 1976.

Izquierdo-Torres, E. \& Harvey, I. (2006) 'A Situated, Embodied and Dynamical Systems Approach to Understanding Learning and Memory'. Paper delivered at the 50th Anniversary Summit of Artificial Intelligence. Monte Verita, Switzerland, 9-14 July 2006.

Malcolm, N. (1977) Memory and Mind. Cornell University Press.

Metcalfe, J. et al (1994) 'Cognitive Binding' in Schacter \& Tulving (1994), 369-394

Moyal-Sharrock, D. 
(2004/2007) Understanding Wittgenstein's On Certainty (Basingstoke: Palgrave Macmillan).

(2007) 'Wittgenstein on Psychological Certainty' in Perspicuous Presentations: Essays on Wittgenstein's Philosophy of Psychology, ed. D. Moyal-Sharrock (Basingstoke: Palgrave Macmillan, 2007), 211-35.

Parkin, A. J.

(1997) Memory \& Amnesia: An Introduction. $2^{\text {nd }}$ Ed. (Oxford: Blackwell).

(1999) Memory: A Guide for Professionals (Chichester, UK: John Wiley \& Sons).

Roediger, H.L. et al (1999) "Components of Processing" in Foster \& Jelicic (1999), 31-65.

Schacter, D.L. (1996) Searching for Memory: the brain, the mind, and the past (New York: Basic Books).

Schacter, D. L. \& E. Tulving (eds) (1994) Memory Systems 1994. Cambridge, Mass., MIT Press.

Schacter, D. L. \& E. Tulving (1994) 'What are the memory systems of 1994?' in Schacter \& Tulving (eds) (1994), 1-29.

Squire, L. R.

(1994) 'Declarative \& Nondeclarative Memory: Multiple Brain Systems Supporting Learning \& Memory' in Schacter \& Tulving (1994), 203-231.

(1999) 'Memory, Human Neuropsychology' MIT Encyclopedia of the Cognitive Sciences, 520-22.

Stern, D.G. (1991) 'Models of Memory: Wittgenstein and Cognitive Science' Philosophical Psychology 4:2, 203-18.

Terrace, H.S. \& Metcalf, J. (2005) The Missing Link in Cognition: Origins of SelfReflective Consciousness (Oxford: Oxford University Press).

Toth, J. P. \& Hunt, Reed R. (1999) 'Not one versus many, but zero versus any: structure and function in the context of the multiple memory systems debate' in Foster \& Jelicic (1999), 232-72.

Toth, J. P. (2000) 'Nonconscious Forms of Human Memory' in Tulving \& Craik (2000), 245-261.

Tulving, E.

(1993)'Varieties of consciousness and levels of awareness in memory' in A. Baddeley \& L. Weiskrantz (eds) Attention: Selection, Awareness, and Control. A Tribute to Donald Broadbent (Oxford, Clarendon Press, 1993), 283-299. (1999) 'Study of memory: processes and systems' in Foster et al (1999), 11-30. (1999a) 'Episodic \& Semantic Memory' MIT Encyclopedia of the Cognitive Sciences, 278-9.

(2002) 'Episodic Memory \& Common Sense: How Far Apart?' in Baddeley et al (2002), 269-88. 
(2005) 'Episodic Memory \& Autonoesis: Uniquely Human?' in Terrace \& Metcalf (2005), 3-56.

Tulving, E. \& Craik, F.I.M. (2000) The Oxford Handbook of Memory (Oxford: Oxford University Press).

Wittgenstein, L.

AWL Wittgenstein's Lectures: Cambridge, 1932-1935, from the notes of A. Ambrose and M. MacDonald. A. Ambrose (ed.) Oxford: Blackwell, 1979.

BrB The Brown Book in The Blue and Brown Books, 2nd ed. Oxford: Blackwell, 1969.

LPE Notes for Lectures on "Private Experience' and 'Sense Data' in Philosophical Occasions: 1912-1951. J.C. Klagge and A. Nordman (eds). Indianapolis: Hackett Publishing, 1993, 202-367.

LPP Wittgenstein's Lectures on Philosophical Psychology 1946-47, notes by P.T. Geach, K.J. Shah and A.C. Jackson, ed. P.T. Geach. Hassocks: Harvester Press, 1988.

LW I Last Writings on the Philosophy of Psychology. Volume I. Edited by G. H. von Wright and H. Nyman. Trans. C. G. Luckhardt and M. A. E. Aue. Oxford: Blackwell, 1982.

LW II Last Writings on the Philosophy of Psychology. Volume II. Edited by G.H. von Wright and H. Nyman (eds). Trans. C.G. Luckhardt and M.A.E. Aue. Oxford, Blackwell, 1992.

OC On Certainty. G.E.M. Anscombe and G.H. von Wright (eds). Trans. D. Paul and G.E.M. Anscombe. Amended 1st Ed. Oxford: Blackwell, 1997.

PG Philosophical Grammar, ed. R. Rhees, tr. A. Kenny. Oxford: Blackwell, 1974.

PI Philosophical Investigations. Trans. G.E.M. Anscombe. 2nd Ed. Oxford: Blackwell, 1997.

PLP The Principles of Linguistic Philosophy, by F. Waismann, ed. R. Harré, 2nd Ed. London: Macmillan, 1997.

RPP I Remarks On The Philosophy of Psychology, vol. I, ed. G.E.M. Anscombe and G.H. von Wright, trans. G.E.M. Anscombe, Oxford: Blackwell, 1980.

Z Zettel. G.E.M. Anscombe and G.H. von Wright (eds). Trans. G.E.M. Anscombe. Berkeley: University of California Press, 1970. 